\title{
Comparison of General Health of the Older Adult Population by Age and Sex
}

\author{
Miwon $\mathrm{Kim}^{1}$ \\ ${ }^{1}$ Associate Professor, Nursing Department, Sangmyung University, kmw@smu.ac.kr
}

\begin{abstract}
The aim of the study was to examine the changes in health status by age and sex in the older adult population in order to assist development of health care programs that are attuned to the characteristics of the elderly age group and sex. The data for this study was obtained from 72,503 older adults, aged 65 years or older, who responded in the 2018 Community Health Survey (Korea Center for Disease Control and Prevention). To gain a deeper understanding of the changes in health status by age and sex, then, age was divided into 5-year interval classes comprising 65-69, 70-74, 75-79, 80-84, 8589 , and $\geq 90$ years groups, with each age group further divided according to sex, resulting in a total of 12 groups for comparison of frequency and percentage of the study variables. The data were analyzed using the statistical program SPSS 18.0 to perform X2 test. The significance level for all statistical analyses was set at the level of $p<0.05$. The results of this study showed that all variables, with the exception of stress experience in men, significantly differed according to age. The factors that differed most markedly according to age were mobility discomfort, chewing difficulty, and perceived health, and factors that differed most markedly according to sex were mobility discomfort, sleep quality, and pain. Women showed poorer health conditions in all parameters compared to men. Therefore, the findings confirm that estimating the health-related variables of older adults without considering their age and sex may not be appropriate to represent a particular age group of older adults. Based on these results, it would be effective to develop elderly health management programs with consideration of the unique characteristics of sex and each age group.
\end{abstract}

Keywords: Community Health Survey, Older Adults, Mobility Discomfort, Sleep Quality

\section{Introduction}

\subsection{Rationale for the Study}

As of 2020 , older adults ( $\geq 65$ years) account for $15.7 \%$ of the total population in South Korea because of increased lifespan. The older adult population is projected to reach $20.3 \%$ in 2025 and $46.5 \%$ in 2067 [1]. Thus, by definition, Korean society has already become an aged society with more than $14 \%$ of the population aged 65 years or older, and will become a super-aged society with more than $20 \%$ of the population aged 65 years or older in 2025[1]. The $\geq 65$ years sector of the population has become a population with a long remaining lifespan of 35 years from 65 to 100 years. Although life expectancy has increased, the simple extension of lifespan accompanied by disease and frailty is not a blessing. Socalled "successful aging," characterized by disease-free and disability-free aging with good cognitive and physical functioning, active life, and good health, is crucial for a happy later life[2]. Maintaining good health among the older adult population is important not only in terms of individuals' quality of life but also from social perspectives such as family burden and health insurance finance[2]. With the

Received: September 10, 2020; 1st Review Result: October 30, 2020; 2nd Review Result: December 15, 2020 Accepted: January 25, 2021 
advanced age of the older adult population, this population can be further divided based on various features, such as health, living environment, educational level, and economic level. Hence, the unique features of these subgroups must be understood and considered when developing health management programs for older adults[3]. Some of the basic factors by which older adults are further divided into subgroups are sex and age. In an era in which the population aged $\geq 80$ years is rising with increased average life expectancy, it is difficult to view the younger elderly population aged 65 years or older to be a group with identical physical and social features[3]. In response, there is ongoing research on whether to understand the population aged $\geq 80$ years as an extension of older adulthood, the final period in the life cycle, or to consider it as a separate period of the life cycle; that is, there is discussion about how to subclassify the older adult population by age[4]. Some studies[3-5] classify the older adult population into the young-old (65-74 years) and old-old ( $\geq 75$ years), or old age (75-84 years), old-old age (85-94 years), and oldest-old age ( $\geq 95$ years). Bae[4] reported that health determinants are different for the young-old (65-74) and old-old ( $\geq 74)$, and that considering the $\geq 65$ years population as a single older adult population without regard to the diverse features in age groups and extended older adulthood neglects the age-specific differences within the older adult population and extended older adulthood. In addition, Park, Kim, and Shim[6] reported that the effects of a cognitive stimulation program for older adults differed between age groups divided with reference to the age of 80 years, based on which they suggested that these programs should be tailored to specific age groups. As shown here, the levels of frailty, disease, and activity limitations differ between young elderly and old elderly, and consequently, there are great gaps in their health care and social care needs[2].

However, previous studies that examined differences among older adult age groups applied varying age criteria, which limit the interpretation of the study findings. Furthermore, although the sex ratio among the older adult population differs from that in other age groups, where the percentage of women increases with advancing age, most studies on the health and quality of life of the elderly, including those by Cho and Chung[5] and Kim, Lee, and Lee[7], reported neither age-specific nor sex-specific differences in their results.

The purpose of this study is to identify the differences in health status by age and sex within the elderly population and to identify changes in health status by age. The results of this study is intended to help to differentiate the characteristics of subgroups based on different ages and between the sexes within the elderly population.

\section{Methods}

\subsection{Material}

This study used raw data from the 2018 Community Health Survey (CHS)[8] of the entire population of elderly aged $\geq 65$ years $(n=72,503)$. The data was divided according to sex and age to investigate the changes of general characteristics, health behaviors, and health by sex and age."

\subsection{Instrument}

To gain a closer examination of the changes and differences in major health-related characteristics according to age, we divided the participants into 5-year age units into six age groups (65-69, 70-74, 75 $79,80-84,85-89, \geq 90$ years) and divided each group into two sex groups, for a total of 12 groups to examine the frequency and percentage of each parameter according to age and sex.

The variables of health status included perceived health, sleep quality, chewing difficulty, pain/discomfort, anxiety/depression, stress, and cognitive disorders of the 2018 National Health Survey questionnaire. In the raw data, each of these variables was rated on a 5-point, 4-point, or 3-point scale, 
and we redefined and reclassified the results for analysis.

\subsection{Statistical Analysis}

The data were analyzed using SPSS PC ver. 18.0, and the significant level of $\alpha$ of the statistical test was $.05 . \chi 2$-test was used to identify differences among age groups in general characteristics, health levels, and to identify between the sexes in characteristics and health status by age group.

\subsection{Ethical Considerations}

The raw data of the 2018 CHS used in this study conforms with the Personal Information Protection Act and the Statistics Act, and only the unidentifiable data were provided from the survey to keep the confidentiality of personal information of the respondents. As the data were officially disclosed to the public, the researcher downloaded and used the data after becoming familiar with the "Regulations on Disclosure and Utilization of Raw Data for CHS" on the website of the National Health Survey (https://chs.cdc.go.kr/chs/examinCn/examinCnMain.do).

\section{Results}

\subsection{General Characteristics by Sex and Age}

General characteristics by sex and age are as shown in [Table 1]. Regarding the age distribution of the entire older adult population, 33.1\% were in the 60-64 years group, while there were lower percentages of more advanced age groups, with $13.4 \%$ in the $80-84$ years group and $1.2 \%$ in the $\geq 90$ years group. A majority (57.8\%) of the population were in the young-old population under the age of 75 years.

[Table 1] General characteristics by Age, sex

\begin{tabular}{|c|c|c|c|c|c|c|c|c|c|c|}
\hline Variables & Categories & & $65-69$ & $70-74$ & $75-79$ & $80-84$ & 85-89 & $\begin{array}{l}\text { Above } \\
90\end{array}$ & Total & $X^{2} / p$ \\
\hline Age & Age & & $\begin{array}{l}24,004 \\
(33.1)\end{array}$ & $\begin{array}{l}17,907 \\
(24.7)\end{array}$ & $\begin{array}{l}16,551 \\
(22.8)\end{array}$ & $\begin{array}{l}9,734 \\
(13.4)\end{array}$ & $\begin{array}{l}3,469 \\
(4.8)\end{array}$ & $\begin{array}{l}838 \\
(1.2)\end{array}$ & $\begin{array}{l}72,503 \\
(100.0 \\
)\end{array}$ & \\
\hline \multirow{3}{*}{ Sex } & \multicolumn{2}{|l|}{ Men } & $\begin{array}{l}10,771 \\
(44.9)\end{array}$ & $\begin{array}{l}7,639 \\
(42.7) \\
\end{array}$ & $\begin{array}{l}6,591 \\
(39.8)\end{array}$ & $\begin{array}{l}3,514 \\
(36.1)\end{array}$ & $\begin{array}{l}1,062 \\
(30.7)\end{array}$ & $\begin{array}{l}208 \\
(24.9)\end{array}$ & $\begin{array}{l}29,785 \\
(41.1)\end{array}$ & \multirow{3}{*}{$\begin{array}{l}517.7 . \\
000\end{array}$} \\
\hline & \multicolumn{2}{|l|}{ Women } & $\begin{array}{l}13,227 \\
(55.1)\end{array}$ & $\begin{array}{l}10,263 \\
(57.3)\end{array}$ & $\begin{array}{l}9,948 \\
(60.2)\end{array}$ & $\begin{array}{l}6,204 \\
(63.9) \\
\end{array}$ & $\begin{array}{l}2,397 \\
(69.3) \\
\end{array}$ & $\begin{array}{l}625 \\
(75.1)\end{array}$ & $\begin{array}{l}42,664 \\
(58.9)\end{array}$ & \\
\hline & \multicolumn{2}{|l|}{ total } & $\begin{array}{l}24,004 \\
(100.0)\end{array}$ & $\begin{array}{l}17,907 \\
(100.0)\end{array}$ & $\begin{array}{l}16,551 \\
(100.0)\end{array}$ & $\begin{array}{l}9,734 \\
(100.0 \\
) \\
\end{array}$ & $\begin{array}{l}3,469 \\
(100.0 \\
)\end{array}$ & $\begin{array}{l}838 \\
(100.0 \\
) \\
\end{array}$ & $\begin{array}{l}72,503 \\
(100.0 \\
)\end{array}$ & \\
\hline \multirow{5}{*}{$\begin{array}{l}\text { Basic } \\
\text { livelihood } \\
\text { recipients }\end{array}$} & \multirow{2}{*}{ Men } & Yes & $\begin{array}{l}467 \\
(4.3)\end{array}$ & $\begin{array}{l}333 \\
(4.4)\end{array}$ & $\begin{array}{l}332 \\
(5.0)\end{array}$ & $\begin{array}{l}192 \\
(5.5)\end{array}$ & $\begin{array}{l}66 \\
(6.2)\end{array}$ & $\begin{array}{l}17 \\
(8.2)\end{array}$ & $\begin{array}{l}1,407 \\
(4.7)\end{array}$ & \multirow{2}{*}{$\begin{array}{l}294.4 \\
.000\end{array}$} \\
\hline & & No & $\begin{array}{l}10,304 \\
(95.7)\end{array}$ & $\begin{array}{l}7,306 \\
(95.6)\end{array}$ & $\begin{array}{l}6,529 \\
(95.0)\end{array}$ & $\begin{array}{l}3,322 \\
(94.6)\end{array}$ & $\begin{array}{l}996 \\
(93.8)\end{array}$ & $\begin{array}{l}191 \\
(91.8)\end{array}$ & $\begin{array}{l}28,648 \\
(95.3)\end{array}$ & \\
\hline & \multirow{2}{*}{ Women } & Yes & $\begin{array}{l}632 \\
(4.8)\end{array}$ & $\begin{array}{l}654 \\
(6.4)\end{array}$ & $\begin{array}{l}792 \\
(8.0)\end{array}$ & $\begin{array}{l}547 \\
(8.8)\end{array}$ & $\begin{array}{l}249 \\
(10.4)\end{array}$ & $\begin{array}{l}73 \\
(11.7)\end{array}$ & $\begin{array}{l}2,947 \\
(6.9)\end{array}$ & \multirow{3}{*}{$\begin{array}{l}244.3 \\
.000\end{array}$} \\
\hline & & No & $\begin{array}{l}12,595 \\
(95.2)\end{array}$ & $\begin{array}{l}9,609 \\
(93.7)\end{array}$ & $\begin{array}{l}9,156 \\
(92.1) \\
\end{array}$ & $\begin{array}{l}5,657 \\
(91.2) \\
\end{array}$ & $\begin{array}{l}2,148 \\
(89.6) \\
\end{array}$ & $\begin{array}{l}552 \\
(88.3) \\
\end{array}$ & $\begin{array}{l}39,717 \\
(93.1) \\
\end{array}$ & \\
\hline & $X^{2} / p$ & & $\begin{array}{c}7.0 \\
.030 \\
\end{array}$ & $\begin{array}{r}51.3 \\
.000 \\
\end{array}$ & $\begin{array}{r}74.1 \\
.000 \\
\end{array}$ & $\begin{array}{l}38.9 \\
.000 \\
\end{array}$ & $\begin{array}{r}26.2 \\
.000 \\
\end{array}$ & $\begin{array}{l}2.0 \\
.369 \\
\end{array}$ & $\begin{array}{l}148.0 \\
.000 \\
\end{array}$ & \\
\hline \multirow[b]{2}{*}{ Spouse } & \multirow[b]{2}{*}{ Men } & $\begin{array}{l}\text { Living with } \\
\text { spouse }\end{array}$ & $\begin{array}{l}9,428 \\
(87.6)\end{array}$ & $\begin{array}{l}6,745 \\
(88.4)\end{array}$ & $\begin{array}{l}5,787 \\
(87.8)\end{array}$ & $\begin{array}{l}2,942 \\
(83.7)\end{array}$ & $\begin{array}{l}785 \\
(73.8)\end{array}$ & $\begin{array}{l}119 \\
(56.9)\end{array}$ & $\begin{array}{l}25,806 \\
(86.7)\end{array}$ & \multirow{2}{*}{$\begin{array}{l}1,562 \\
2 \\
.000\end{array}$} \\
\hline & & $\begin{array}{l}\text { Divorce, } \\
\text { bereaveme } \\
\text { nt, etc }\end{array}$ & $\begin{array}{l}1,338 \\
(12.4)\end{array}$ & $\begin{array}{l}889 \\
(11.6)\end{array}$ & $\begin{array}{l}802 \\
(12.2)\end{array}$ & $\begin{array}{l}573 \\
(16.2)\end{array}$ & $\begin{array}{l}279 \\
(26.2)\end{array}$ & $\begin{array}{l}90 \\
(43.1)\end{array}$ & $\begin{array}{l}3,971 \\
(13.3)\end{array}$ & \\
\hline
\end{tabular}




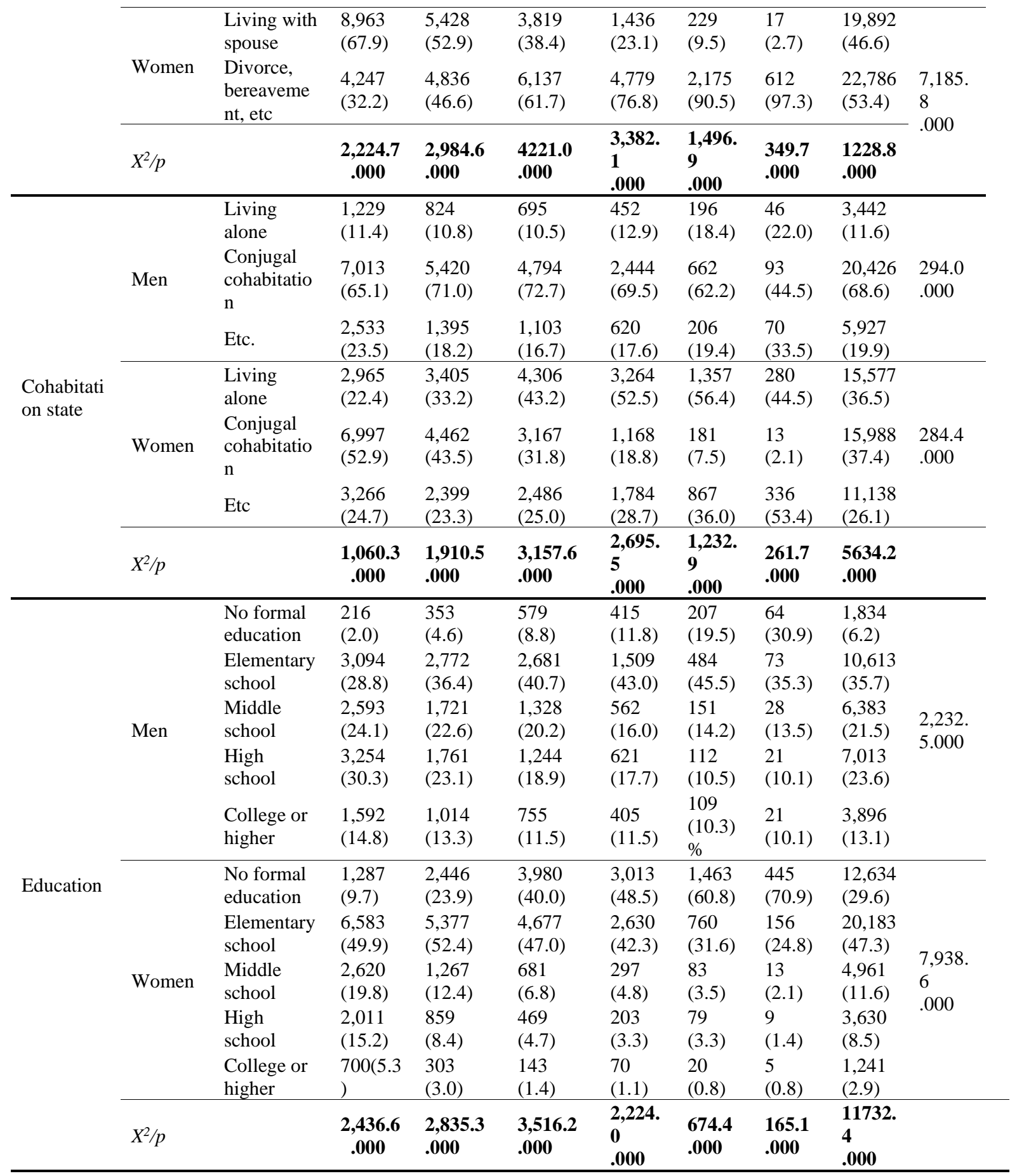

The sex ratio was $41.1 \%$ men and $58.9 \%$ women. This ratio did not markedly differ in the $65-70$ years group ( $44.9 \%$ vs $55.1 \%$ ), but the percentage of women increased with advancing age, to $39.8 \%$ men and $60.2 \%$ women in the $75-80$ years group, and $24.9 \%$ men and $75.1 \%$ women in the $\geq 90$ years group. There were more women who were basic livelihood recipients $(6.9 \%)$ than were men $(4.7 \%)$. The proportion of basic livelihood recipients increased with advancing age, from $4.3 \%$ men and $4.8 \%$ women in the $65-70$ years group to $6.2 \%$ men and $10.4 \%$ women in the $85-90$ years group. This result highlights the need to pay attention to poverty status in older adults, particularly older women.

Regarding cohabitation, $66.7 \%$ of men lived with a spouse, while $46.6 \%$ of women lived with a spouse. The percentage of individuals who are currently living with their spouse was markedly higher among men than women, and this gap increased with advancing age, where $83.7 \%$ of men aged 80 
reported living with their spouse while only $23.1 \%$ of women reported living with their spouse. This phenomenon is associated with the higher percentage of older women living alone.

In terms of individuals living alone, there were more women living alone (36.5\%) than men living alone (11.6\%). This percentage was $11.4 \%$ in men and $22.24 \%$ in women in the $65-69$ years group, but the gap intensified in the $80-84$ years group to $12.9 \%$ in men and $52.5 \%$ in women.

Regarding educational level, there were sex gaps in all age groups. There were about five times more women with no formal education $(29.6 \%)$ than men (6.2\%), and there were about four times more highly educated (college or higher) men (13.1\%) than highly educated women $(2.9 \%)$. The gender gap in lack of education was $60 \%$ in the $\geq 90$ years group but decreased with younger generations to $7.7 \%$ in the 65-69 years group, showing that while older women had fewer educational opportunities than older men, the gap is lessening with younger age groups.

\subsection{Comparison of General Health Status by Sex and Age}

The differences in health by sex and age are shown in [Table 2]. The percentages of older adults in Korea who perceive themselves to be in poor health were $22.2 \%$ in men and $32.9 \%$ in women in the $65-$ 69 years group. However, these percentages increased for both sexes to $52.1 \%$ in men and $56.3 \%$ in women in the 86-89 years group, and in all age groups, women generally perceived themselves to be in poorer health. The $\geq 90$ years group actually perceived themselves to be in better health than the 85-89 years group, with $46.9 \%$ in men and $54.5 \%$ in women having poor perceived health.

Sleep quality was reported to be poor in $18.8 \%$ of men and $31.2 \%$ of women in the $65-69$ years group, but the percentages increased to $28.3 \%$ of men and $38.8 \%$ of women in the $80-84$ years group. Additionally, the percentage of those with poor sleep quality in the $85-90$ years group was $28.3 \%$ in men and $38.8 \%$ in women.

Chewing discomfort continuously worsened with advancing age, with $30.2 \%$ in men and $31.0 \%$ in women in the $65-69$ years group and $53.4 \%$ in men and $62.6 \%$ in women in the $85-89$ years group, with a more drastic exacerbation around age 70 in men and 70,75 in women. Chewing discomfort was generally worse in women than men in all age groups. The overall sex ratio of chewing difficulty was $38.1 \%$ in men and $44.1 \%$ in women, but the age and gender gap widened, ranging from $30.2 \%$ to $62.6 \%$.

The percentage of those with severe pain/discomfort was $2.2 \%$ in men and $4.2 \%$ in women in the 65 69 years group but $8.2 \%$ in men and $15.1 \%$ in women in the $85-89$ years group.

Stress tended to decrease with age, with $14.7 \%$ in men and $21.1 \%$ in women in the $65-69$ years group, $14.7 \%$ in men and $19.4 \%$ in women in the $80-84$ years group, and $12.6 \%$ in men and $10.9 \%$ in women in the $\geq 90$ years group, although it was higher among women than men in all age groups. There were no significant differences in the stress rate across age groups in men, while it decreased with age in women. While there was a large gender gap in stress among the young-old, the gap decreased with advancing age until it was completely lost from age 86 , showing that women young-old have the most severe stress.

[Table 2] General Health Status by Age, sex

\begin{tabular}{|c|c|c|c|c|c|c|c|c|c|c|}
\hline $\begin{array}{l}\text { General } \\
\text { health }\end{array}$ & Sex & Categories & $65-69$ & $70-74$ & $75-79$ & $80-84$ & $85-89$ & Above 90 & Total & $X^{2} / p$ \\
\hline \multirow{5}{*}{$\begin{array}{l}\text { Perceived } \\
\text { health }\end{array}$} & \multirow{2}{*}{ Men } & Poor & $\begin{array}{l}2,396 \\
(22.2)\end{array}$ & $\begin{array}{l}2,220 \\
(29.1)\end{array}$ & $\begin{array}{l}2,377 \\
(36.1)\end{array}$ & $\begin{array}{l}1,591 \\
(45.3)\end{array}$ & $\begin{array}{l}554 \\
(52.1)\end{array}$ & $\begin{array}{l}98 \\
(46.9)\end{array}$ & $\begin{array}{l}9,236 \\
(31.0)\end{array}$ & \multirow{2}{*}{$\begin{array}{l}1096.0 \\
.000\end{array}$} \\
\hline & & Good & $\begin{array}{l}8,377 \\
(77.8)\end{array}$ & $\begin{array}{l}5,416 \\
(70.9)\end{array}$ & $\begin{array}{l}4,209 \\
(63.9)\end{array}$ & $\begin{array}{l}1,923 \\
(54.7)\end{array}$ & $\begin{array}{l}510 \\
(47.9)\end{array}$ & $\begin{array}{l}111 \\
(53.1)\end{array}$ & $\begin{array}{l}20,546 \\
(69.0)\end{array}$ & \\
\hline & \multirow{2}{*}{ Women } & Poor & $\begin{array}{l}4,345 \\
(32.9)\end{array}$ & $\begin{array}{l}4,533 \\
(44.2)\end{array}$ & $\begin{array}{l}5,215 \\
(52.4)\end{array}$ & $\begin{array}{l}3,646 \\
(58.7)\end{array}$ & $\begin{array}{l}1,351 \\
(56.2)\end{array}$ & $\begin{array}{l}343 \\
(54.5)\end{array}$ & $\begin{array}{l}19,433 \\
(45.5)\end{array}$ & \multirow{2}{*}{$\begin{array}{l}1642.9 \\
.000\end{array}$} \\
\hline & & Good & $\begin{array}{l}8,880 \\
(67.2) \\
\end{array}$ & $\begin{array}{l}5,732 \\
(55.8) \\
\end{array}$ & $\begin{array}{l}4,740 \\
(47.6) \\
\end{array}$ & $\begin{array}{l}2,568 \\
(41.3) \\
\end{array}$ & $\begin{array}{l}1,054 \\
(43.8) \\
\end{array}$ & $\begin{array}{l}286 \\
(45.4) \\
\end{array}$ & $\begin{array}{l}2,326 \\
(54.5) \\
\end{array}$ & \\
\hline & $X^{2} / p$ & & 578.2 & 567.9 & 535.0 & 186.8 & 14.1 & 6.5 & $2,076.6$ & \\
\hline
\end{tabular}




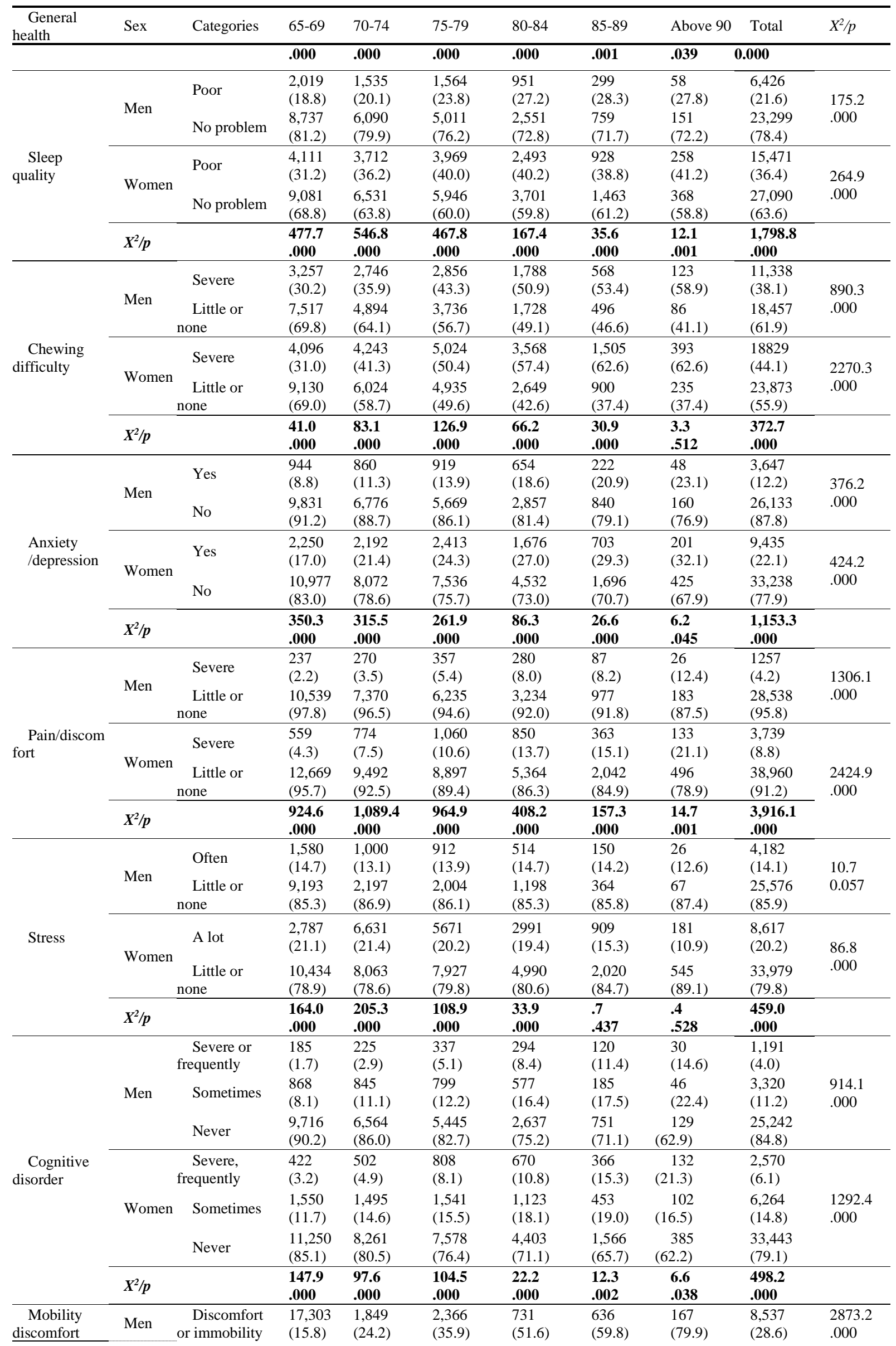




\begin{tabular}{|c|c|c|c|c|c|c|c|c|c|c|}
\hline $\begin{array}{l}\text { General } \\
\text { health }\end{array}$ & Sex & Categories & $65-69$ & $70-74$ & 75-79 & $80-84$ & $85-89$ & Above 90 & Total & $X^{2} / p$ \\
\hline \multirow[t]{4}{*}{ (ambulation) } & & No problem & $\begin{array}{l}9,073 \\
(84.2) \\
\end{array}$ & $\begin{array}{l}5,790 \\
(75.8)\end{array}$ & $\begin{array}{l}4,226 \\
(64.1)\end{array}$ & $\begin{array}{l}1,702 \\
(48.4) \\
\end{array}$ & $\begin{array}{l}428 \\
(40.2) \\
\end{array}$ & $\begin{array}{l}42 \\
(20.1) \\
\end{array}$ & $\begin{array}{l}21,261 \\
(71.4) \\
\end{array}$ & \\
\hline & \multirow{2}{*}{ Women } & $\begin{array}{l}\text { Discomfort } \\
\text { or immobility }\end{array}$ & $\begin{array}{l}3,787 \\
(28.6)\end{array}$ & $\begin{array}{l}4,655 \\
(45.3)\end{array}$ & $\begin{array}{l}5,887 \\
(59.1)\end{array}$ & $\begin{array}{l}4,424 \\
(71.1)\end{array}$ & $\begin{array}{l}1,871 \\
(77.8)\end{array}$ & $\begin{array}{l}537 \\
(85.5)\end{array}$ & $\begin{array}{l}21,160 \\
(49.6)\end{array}$ & \multirow{2}{*}{$\begin{array}{l}5510.1 \\
.000\end{array}$} \\
\hline & & No problem & $\begin{array}{l}9,441 \\
(71.4)\end{array}$ & $\begin{array}{l}5,612 \\
(54.7)\end{array}$ & $\begin{array}{l}4,070 \\
(40.9)\end{array}$ & $\begin{array}{l}1,794 \\
(28.9)\end{array}$ & $\begin{array}{l}534 \\
(22.2)\end{array}$ & $\begin{array}{l}91 \\
(14.5)\end{array}$ & $\begin{array}{l}21,542 \\
(50.4)\end{array}$ & \\
\hline & $X^{2} / p$ & & $\begin{array}{l}574.3 \\
.000\end{array}$ & $\begin{array}{l}859.1 \\
.000\end{array}$ & $\begin{array}{l}882.1 \\
.000\end{array}$ & $\begin{array}{l}384.3 \\
.000\end{array}$ & $\begin{array}{l}119.9 \\
.000\end{array}$ & $\begin{array}{l}4.9 \\
.088\end{array}$ & $\begin{array}{l}3,216.9 \\
.000\end{array}$ & \\
\hline \multirow{2}{*}{ Total } & Men & & $\begin{array}{l}10,776 \\
(100.0) \\
\end{array}$ & $\begin{array}{l}7,640 \\
(100.0)\end{array}$ & $\begin{array}{l}6,592 \\
(100.0)\end{array}$ & $\begin{array}{l}3,516 \\
(100.0)\end{array}$ & $\begin{array}{l}1,064 \\
(100.0)\end{array}$ & $\begin{array}{l}209 \\
(100.0)\end{array}$ & $\begin{array}{l}29,797 \\
(100.0)\end{array}$ & \\
\hline & Women & & $\begin{array}{l}13,228 \\
(100.0)\end{array}$ & $\begin{array}{l}10,267 \\
(100.0)\end{array}$ & $\begin{array}{l}9,959 \\
(100.0)\end{array}$ & $\begin{array}{l}6,218 \\
(100.0)\end{array}$ & $\begin{array}{l}2405 \\
(100.0)\end{array}$ & $\begin{array}{l}629 \\
(100.0)\end{array}$ & $\begin{array}{l}42,706 \\
(100.0)\end{array}$ & \\
\hline
\end{tabular}

The prevalence of anxiety and depression was $8.8 \%$ in men and $17.0 \%$ in women in the $65-69$ years group but increased to $20.9 \%$ in men and $29.3 \%$ in women in the $85-89$ years group, showing an increasing trend with advancing age. The prevalence of anxiety and depression was also higher in women than men in all age groups.

The prevalence of severe cognitive disorder (frequent, severe) was $1.7 \%$ in men and $3.2 \%$ in women in the 65-69 years group, but it consistently increased with age in both sexes to $8.4 \%$ in men and $10.6 \%$ in women in the $80-84$ years group, and $14.6 \%$ in men and $21.3 \%$ in women in the $\geq 90$ years group, showing that at least one out of ten people after the age of 85 in men and 80 in women experience severe or frequent cognitive disorder. In terms of sexes, the prevalence was higher in women than men in all age groups.

The prevalence of mobility discomfort (or immobility) was $15.8 \%$ in men and $28.6 \%$ in women in the 65-69 years group but increased with age to $51.6 \%$ in men and $71.1 \%$ in women in the $81-84$ years group and $79.9 \%$ in men and $85.5 \%$ in women in the $\geq 90$ years group.

\subsection{The Changes in General Health According to Age and Sex}

The changes in general health according to age and sex as discussed above are presented in [Fig. 1] and [Fig. 2]. As shown in the graph, the negative health-related variables were all higher in women than in men, suggesting that while women may live longer, their health is poorer than that of men. The factors that dramatically change according to age in both men and women were chewing difficulty, mobility disorder, perceived health, and anxiety/depression.

\section{Discussion}

According to the results of this study, which analyzed people aged 65 or older, all variables differed greatly by age. Therefore, it may not be appropriate to apply the total elderly population's average without age considerations to a particular age group. In the following section, we review the results for each variable.

The proportion of older adults who perceived that they were in poor health increased as they grew older. Among all participants, $31.9 \%$ of men and $45.5 \%$ of women reported poor self-perceived health. In the 65-69 age group, the proportions of men and women who perceived poor health were $22.2 \%$ and $32.9 \%$, respectively, whereas in the $85-89$ age group, it increased to $52.1 \%$ for men and $56.2 \%$ for women. Although these findings are from the same older population, the differences varied depending on the age group. Therefore, it has been confirmedcan be suggested that estimating perceived health status of older adults without considering their age group may not be appropriate to represent a particular age group. 


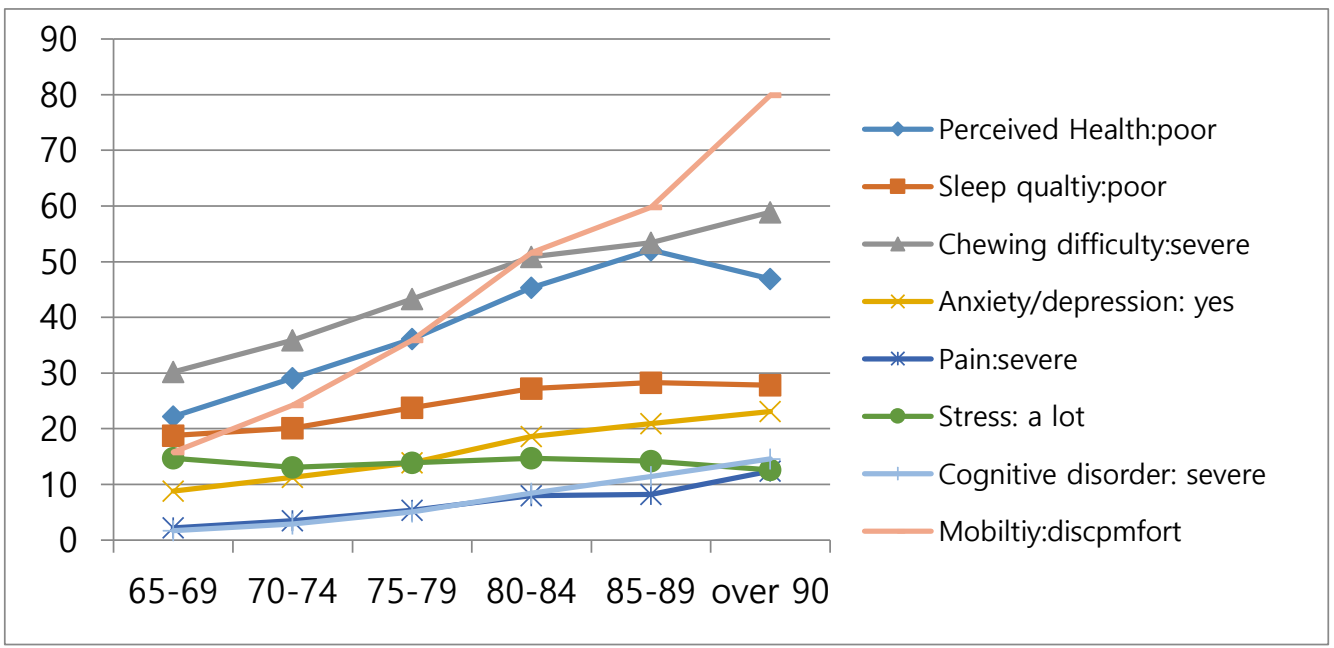

[Fig. 1] General Health Status Change by Age of Men

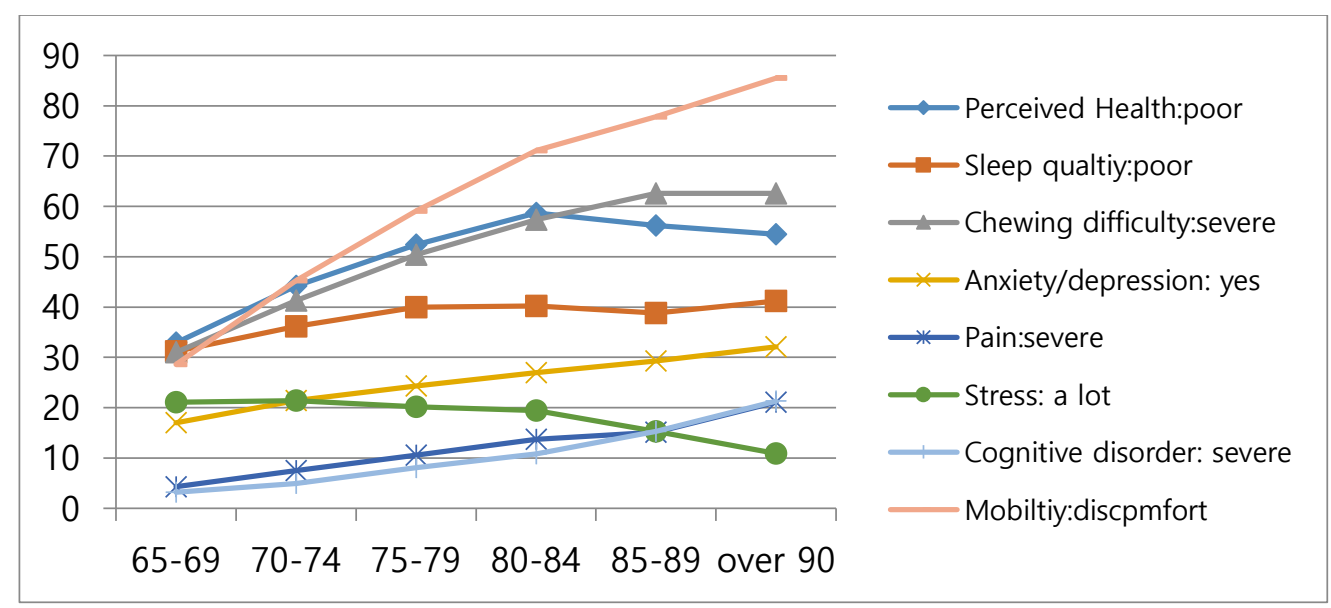

[Fig. 2] General Health Status Change by Age of Women

Cho and Chung[5] reported that many studies classify older adulthood with reference to the age of 75 years to examine the physical and emotional differences within the population. However, according to our analysis by sex, the gap intensified with reference to age 80 in men and age 75 in women, suggesting that there are also sex-specific differences in perceived health status. While perceived health status is subjective, it is an important individual health indicator, as it represents an individual's opinions about their own health status most sensitively, which cannot be measured using medical tests[9].

Sleep difficulties are the most common health-related complaint among older adults[10], and Jeon and Choi[11] reported that $67.2 \%$ of their participants met the criteria for insomnia based on selfrecorded sleep logs. However, in the present study, the percentage of those with poor sleep quality in the $85-90$ years group was $28.3 \%$ in men and $38.8 \%$ in women, which was lower than that reported in previous studies, and this may be attributable to the differences in the instruments used to measure sleep quality. Furthermore, considering that subjectively assessed sleep quality, as used in this study, is not correlated with actual sleep[11], it cannot be concluded that this subjective indicator accurately reflects insomnia in older adults. In this study, difficulty chewing varied greatly from $30.2 \%$ to $62.6 \%$ by age group. This result means that age needs to be considered when dealing with difficulty chewing in older people. Ju, Kim, and Son[12] reported no differences in chewing problems between sexes, but in our study, a higher percentage of older women complained of chewing difficulty compared to older men in all age groups, with the exception of the $\geq 90$ years group. Chewing difficulty makes eating difficult, which would worsen the overall health status, and worsening of oral health itself is a risk factor for 
cognitive impairment[13]. To boost older adults' health-related quality of life, it is necessary to provide education and support for oral health from early older adulthood to prevent deterioration of oral health with advanced age.

The percentage of respondents suffering severe pain/discomfort was about twofold higher in women than men in all age groups, showing that pain and discomfort are more common problems for women. These results are in line with those of Choi and Park[14], in which pain was higher among those aged 80 years or older than those aged 70-74 years, and higher among women than men. Pain is reported to be correlated with several problems, such as depression, quality of life, and perceived health status. In older adults, chronic pain is extremely common, and it is mainly caused by arthritis, low back pain, and bone and joint problems[15]. However, understanding pain epidemiology in older adults is inadequate, with the prevalence of chronic pain in older adults reported to range from $25 \%-50 \%$ or $2 \%-40 \%[15]$. Considering the large difference in the percentages of individuals with severe pain across age groups, with a range of $2.2 \%-12.4 \%$ in men and $4.3 \%-21.1 \%$ in women in this study, simply examining the older adult population ( $\geq 65$ years) as a single group could result in large gaps in results across studies. Thus, dividing the older adult population by age group would help gain a more accurate understanding of the health problems of specific age groups.

Stress tended to decrease with age, and it was higher among women than men in all age groups. There were no significant differences in the stress rate across age groups in men, while it decreased with age in women. While there was a large gender gap in stress among the young-old, the gap decreased with advancing age until it was completely lost from age 86 , showing that women under 85 had the most severe stress.

Depression in older adults worsened with advancing age, as older adults' social positions and roles are diminished further as they age, highlighting the need to pay attention to old older adults[16]. The higher prevalence of depression in older women than older men in this study is in line with the results of Kim, Lee, and Jung[17], in which the prevalence of long-term depression was more than twofold higher in older women $(22.6 \%)$ than older men $(9.3 \%)$. And other reports, including that by Park, Kim[18], in which the prevalence of depression was higher among older women than in older men. In this study, the mean prevalence was $12.2 \%$ in men and $22.1 \%$ in women, which is similar to the results of Kim, Lee, and Jung[17]. However, when examined by sex and age groups, the prevalence ranged widely from $8.8 \%$ in men in the $65-69$ years group to $32.1 \%$ in women in the $\geq 90$ years group, which vastly differs from the findings of previous studies on older adults that did not take age and sex into consideration.

This study showed that the prevalence of severe cognitive disorder (frequent, severe) was higher in women than men in all age groups. However, considering that Park and Kim[18] reported higher cognitive functioning in men in a simple comparison of means but no gender gap after controlling for education and age in their study on the differences in the predictors of cognitive function in older men and women in Korea, sex-specific differences should be interpreted carefully. As shown in our study, the percentage of individuals experiencing cognitive disorder increases with age, and considering that recovery is difficult once cognitive disorder is exacerbated and that it poses serious harm to individuals and their families, individual and social attention and policies are needed to help maintain cognitive functions from early older adulthood or even before that.

In this study the prevalence of mobility discomfort (or immobility) rapidly increased with age. Mobility is the most basic requirement for movement and exercise for older adults in order to carry on an independent life, but as shown in our results, the percentage of older adults with mobility difficulties dramatically spikes from age 80 . In a study on the predictors of quality of life by sex by Lee[19], the factor with the greatest impact on health-related quality of life was activity limitation in both older men and women, suggesting that mobility is a major factor that affects various health problems in older adulthood. Mobility induces a number of problems in older adults. Such a marked rise in the percentage 
of older adults with activity restrictions due to mobility discomfort or immobility with advancing age as shown in our study would hinder their access to health care in an environment lacking family support[2]. Loss of physical functioning such as movement, that is, walking[3], increases the risk for depression symptoms, which in turn further curtails movement in older adults. The adults aged $\geq 80$ years as shown in our study are speculated to be at a high risk for low life satisfaction and depression due to daily stress and difficulties caused by aging. In our study, the percentage of older adults with mobility problems drastically increased with age, suggesting that mobility problems are a serious challenge according to age. However, as there are still a considerable percentage of older adults who do maintain normal physical functioning despite old age, new studies need to identify the predictors by examining the characteristics of the oldest-old who maintain good physical and mental health. These results show that older women are at a high risk of facing financial poverty and suffer from consequent physical and emotional difficulties.

Given the general change in health over time, factors that dramatically changed with age were chewing difficulty, mobility disorders, perceived health, and anxiety/depression.

In terms of changes in general health by age, negative health-related variables all showed at higher levels in women than men, suggesting that women may live longer, but their health status is worse than for men. In particular, subjective perceptions such as anxiety, pain, and depression were found to be worse for women, and mental health, such as depression and stress, is highly correlated with the quality of life of the elderly[19]. Furthermore, the results for the old-old population, which is expanding due to increased life expectancy, have shed light on the limitations of the existing activity theory and successful aging theory, which viewed older adulthood as a single period in an individual's life cycle[20].

\section{Conclusions}

In this study, all study variables, with the exception of stress, significantly differed according to age in both men and women. The findings suggest that investigating the health variables of the entire older population without considering their age group is not appropriate to represent the health variables of a particular age group of older adults, because the health variables of the overall older population differ from those of the a particular age group. Moreover, there were significant differences between men and women for all the study variables, with negative variables such as poor perceived health, sleep quality, chewing difficulty, pain/discomfort, stress, cognitive disorder, and mobility being more prevalent among older women. The greatest gender gaps were in mobility, perceived health, and sleep quality. These results suggest that older women are at high risk of facing financial poverty, and suffering from consequent physical and emotional difficulties, calling for programs that focus on this specific group.

Based on these results, existing services for the elderly that consider the older adult population as a homogeneous group should be tailored to specific sex and age groups in order to provide a more effective custom-built service. Furthermore, it is necessary to consider sex differences when developing health and welfare policies for the elderly.

This study analyzed data for 2018 only, thus, there are limitations in applying the results to other years. Additionally, all health status variables in this study are responses to subjective surveysand may not be the same as results obtained in objective conditions.

Future studies should examine the physical, social, and psychological differences according to age in older adults to investigate the characteristics of the population in more detail.

\section{References}

[1] Korean Statistical Information Service (KOSIS), 2020 old man factual survey, https://kostat.go.kr/ portal/ 
korea/kor_nw/3/index.board?bmode=read\&aSeq=370781\&pageNo=\&rowNum=10\&amSeq $=\&$ sTarget $=\& s T x t=$, Sep $01(2020)$

[2] E. J. Park, Health Status in Old Age and Its Policy Implications, Health and Welfare Forum, (2016), No. 240, pp.61-70.

[3] J. Cohen-Mansfield, D. Shmotkin, Z. Blumstein, A. Shorek, N. Eyal, H. Hazan, The Old, Old-Old, and the Oldest Old: Continuation or Distinct Categories? An Examination of the Relationship between Age and Changes in Health, Function, and Wellbeing, The International Journal of Aging and Human Development, (2013),Vol.77, No.1, pp.3757, https://doi.org/10.2190/AG.77.1.c

[4] J. Y. Bae, A Study on Determinants of Health Status of the Elderly by Age Group, 2019 Conference of Korean Society of Gerontological Social Welfare, (2019), pp.209-230.

[5] Y. H. Chung, Y. H. Cho, Health Behaviors, Health Status and Quality of Life among the Young-old and the Old-old in Korea, Korean Public Health Research, (2014), Vol.40, No.1, pp.55-64, DOI : 10.22900/kphr.2014.40.1.005

[6] J. M. Park, M. W, Kim, H. Y. Shim, Effects of a Multicomponent Cognitive Stimulation Program on Cognitive Function Improvement Among Elderly Women, Asian Nursing Research, (2019), Vol.13, No.5, pp.306-312, DOI:https://doi.org/10.1016/j.anr.2019.11.001

[7] J. Y. Kim, S. G. Lee, S. K. Lee, The Relationship between Health Behaviors, Health Status, Activities of Daily Living and Health-related Quality of Life in the Elderly, Journal of the Korean Gerontological Society, (2010), Vol.30, No.2, pp.471-484, UCI : G704-000573.2010.30.2.007

[8] Korea Centers for Disease Control and Prevention, 2018 Community Health Survey, Korea Centers for Disease Control and Prevention, (2018), Seoul, Korea.

[9] K.O. Chang, M. J. Kim, I. J. Kim, Effect of Perceived Health Status, Self-Esteem and Quality of Life on Life Satisfaction of Elders Living at Home, Journal of Korea Academia-Industrial Cooperation Society, (2015), Vol.16, No.7, pp.4723-4733, DOI : 10.5762/KAIS.2015.16.7.4723

[10] S. J. Yang, J. S. Kim, Factors Affecting the Quality of Sleep Among Community Dwelling Elders, Journal of Korean Gerontological Nursing, (2010), Vol.12, No.2, pp.108-118, UCI : G704-SER000008641.2010.12.2.007

[11] B. M, Jeon, S. C. Kwon, Factors Influencing Sleep Disturbances among Older Adults Living within a Community, Korean Journal of Adult Nursing, (2017). Vol.29, No.3, pp.235-245, DOI : 10.7475/kjan.2017.29.3.235

[12] O. J. Ju, I. J. Kim, J. L. Son, Influence of Health-Related Quality of Life (EQ-5D) on Oral Health Problems in the Elderly in the National Health and Nutrition Survey, Journal of the Korea Convergence Society, (2020), Vol.11, No.1, pp.309-315, DOI : 10.15207/JKCS.2020.11.1.309

[13] S. O. Kim, The Relationship between Cognitive Function of the Elderly and Oral Health and Activities of Daily Living, International Journal of Elderly Welfare Promotion and Management, (2019), Vol.3, No.1, pp.1-6.

[14] I. S. Choi, K. S. Park, The Effects of Pain, Sleep, and Depression on Quality of Life in Elderly People with Chronic Pain, Journal of Digital Convergence,(2017), Vol.15, No. 8, pp 289-299, http://dx.doi.org/10.14400/JDC.2017.15.8.289

[15] H. Ka, Chronic Pain Management of the Elderly, Korean Journal of Family Practice, (2012), Vol.2, No.2, Suppl. p.94.

[16] E. R. Lee, J. H. Kang, J. P. Jung, Factors Influencing the Depression of Aged People, The Journal of the Korea Contents Association, (2013), Vol.13, No.7, pp.290-300, https://doi.org/10.5392/JKCA.2013.13.07.290

[17] T. W. Kim, J. M. Lee, J. W. Jung, A Study of Elderly Poverty and Depression: Focusing on the Multidimensional Concept of Poverty, Health and Social Welfare, (2015), Vol.35, No.3, pp.71-102, http://dx.doi.org/ 10.15709/hswr.2015.35.3.71

[18] M. W. Kim, J. M. Park, Factors Affecting Cognitive Function According to Gender in Community-Dwelling Elderly Individuals, Epidemiology and Health, (2017), Vol.39, pp.1-10, https://doi.org/10.4178/epih.e2017054

[19] S. H. Lee. Gender Difference in Influencing Factors on Health related Quality of Life among the Elderly in Community, Journal of Digital Convergence, (2013), Vol.11, No.12, pp.523-535, https://doi.org/10.14400/JDPM.2013.11.12.523

[20] K. H. Sohn, K. H. Kim, Analysis of the Effects of Self-Perceived Health on Life Satisfaction and Mediating Effect of 
Comparison of General Health of the Older Adult Population by Age and Sex

Social Activities of the Elderly by Age Group, Journal of The Korean Contents Association, (2020), Vol.20, No.7, pp.127-138, https://doi.org/10.5392/JKCA.2020.20.07.127 